\title{
Clinical features and outcome in patients with osseomuscular type of Wilson's disease
}

\author{
Hao Yu', Juan-Juan Xie ${ }^{1}$, Yu-Chao Chen², Qin-Yun Dong ${ }^{3}$, Yi Dong ${ }^{1}$, Wang Ni ${ }^{1}$ and Zhi-Ying $\mathrm{Wu}^{1,4^{*}}$
}

\begin{abstract}
Background: Wilson's disease with osseomuscular type is a rare condition, which often lacks typical hepatic and neurological symptoms and causes misdiagnoses easily. During the past 10 years, eight Chinese patients of osseomuscular type of Wilson's disease were identified in our clinic.

Methods: Clinical information was gathered from medical records and follow-ups. The genetic testing was performed in each patient. Serum ceruloplasmin, Kayser-Fleischer rings, liver function, brain magnetic resonance imaging and abdominal ultrasonography were also evaluated.

Results: The median age of onset is 12 years of age. The patients had their initial musculoskeletal conditions with arthralgia or joint deformity, while the hepatic or neurologic signs were minimal. Most patients (6/8) eventually developed clinical neurological symptoms afterwards with a median interval of 36 months. All of them had normal liver function and low serum ceruloplasmin ( $<0.1 \mathrm{~g} / \mathrm{L})$. Most patients (6/8) present with Kayser-Fleischer rings and abnormal hepatic ultrasonography. The arthralgia was resolved with copper chelation therapy.

Conclusions: Wilson's disease with osseomuscular type occurs without typical hepatic or neurological symptoms, which makes the clinical diagnosis challenging. Serum ceruloplasmin, abdominal ultrasonography, ophthalmic examination and genetic testing help to establish the diagnosis. Early diagnosis can initiate an effective treatment and prevent the further damage.
\end{abstract}

Keywords: Arthralgia, ATP7B, Copper, Deformity, Osteoarthritis

\section{Background}

Wilson's disease (WD), also known as hepatolenticular degeneration, is an autosomal recessive disease (incidence 1/ 30,000) characterized by Kayser-Fleischer rings of cornea (K-F rings) and multisystem damage, including liver cirrhosis, neurological symptoms and musculoskeletal deformity. The disease is caused by mutations in the $A T P 7 B$ gene, which encodes a copper-transporting ATPase in the liver. The deficiency in the enzyme activity can lead to a toxic copper accumulation in multiple organs, which may be responsible for its wide variety of symptoms [1].

\footnotetext{
* Correspondence: zhiyingwu@zju.edu.cn

'Department of Neurology and Research Center of Neurology in Second Affiliated Hospital, and the Collaborative Innovation Center for Brain Science, Zhejiang University School of Medicine, 88 Jiefang Rd, Hangzhou 310009, China ${ }^{4} J o i n t$ Institute for Genetics and Genome Medicine between Zhejiang University and University of Toronto, Zhejiang University, Hangzhou, China Full list of author information is available at the end of the article
}

Despite wide varieties of clinical manifestations, WD patients typically present with liver dysfunction or neurological disorders. Musculoskeletal abnormalities, including premature osteoarthritis, skeletal deformity and pathological bone fractures, can be occasionally found in WD patients with hepatic or neurologic type $[2,3]$, but very rare as initial symptoms (incidence $\sim 2 \%$ in Chinese population) [4]. These conditions, also known as "osseomuscular type" of WD, often lack typical hepatic and neurological symptoms and cause misdiagnoses easily $[5,6]$.

During the past 10 years, we have collected and identified eight Chinese WD patients with osseomuscular type in our clinic. Their genotypes, clinical manifestations, biochemical parameters and outcome of treatment are reported herein, aiming to improve early diagnosis and therapy with this condition. 


\section{Methods}

\section{Subjects}

All eight WD patients were diagnosed by genetic testing. The degree of osseomuscular symptoms was based on the published assessment scale (0: Normal. 1: Abnormal skeletal X-ray; asymptomatic.2: Difficulty in ADL but independent. 3: Requires help in ADL. 4: Dependent on others for ADL. 5: Fracture or bedbound) [7]. In addition, ceruloplasmin, K-F rings, liver function, brain magnetic resonance imaging (MRI) and abdominal ultrasonography were also evaluated.

\section{Genotype analysis}

Genomic DNA was extracted from peripheral EDTAtreated blood by Blood Genomic Extraction Kit (Qiagen, Hilden, Germany). The Sanger sequencing of $A T P 7 B$ was performed with a procedure described previously [8].

\section{Results}

\section{Mutation analysis}

All eight patients carried biallelic mutations, and seven of them were compound heterogeneous (Table 1). The most frequent mutation was p.R778L (6/16), which was also the most common mutation of $A T B 7 B$ in Chinese population [9].

\section{Clinical manifestation}

All of patients denied WD family histories. The median age of onset is 12 years of age (range 3-17 years). Their complains were all about musculoskeletal problems such as arthralgia and joint deformity (Table 1). The abnormalities include arthralgia of the knees in four patients, genu varum in two patients, arthralgia of hip joints in one patient, genu valgum in one patient and talipse equinovarus in one patient. The median assessment score of osseomuscular symptoms is 3 (range 2-4).

As an example, Patient 8 is a 13 -year-old boy with a 10-year history of walking difficulty. After a hernia surgery at 3 years of age, he felt knees and ankles sore after taking a long walk. The condition progressed slowly and he got a hip pain at 12 years of age. The pain was aggravated by walking and rapidly made him unable to walk any more. Physical examination revealed a severely limited movement of bilateral hip joint in lower limbs. The motion range of his hip joint was only about $25^{\circ}$ (flexion $45^{\circ}$ to $70^{\circ}$ ). Excessive extension or flexion would elicit intense and sharp pain immediately, so the patient could never straighten his legs. When standing and walking, he had to keep a "crouching" posture with bent hips, and steady himself with hands on knees. His condition had been considered as a rheumatic disease for many years and diagnosed as "arthralgia" or "osteoarthritis" in many hospitals. However, the diagnosis was indefinite and he only received some anti-inflammatory therapy.

Similar to Patient 8, all the other patients also sought for medical attention in orthopedics or rheumatology firstly, due to absence of neurological and hepatic symptoms. Moreover, four patients (Patient 1, 4, 5, 6) with deformities subsequently underwent the orthopedic surgeries. However, the orthopedic surgery did not correct the skeletal abnormalities and neurological deterioration ensued. Patients 1 and 6 showed neurological symptoms shortly after surgeries ( $<2$ months) and the other two developed neurological symptoms after 15 and 36 months respectively (Table 1 ).

Despite the absence of neurological complaints initially, it is noteworthy that most patients (6/8) eventually developed neurological symptoms afterwards with a median interval of 36 months (range 8-84 months), including

Table 1 Genotype and clinical course in eight cases of WD with osseomuscular type

\begin{tabular}{|c|c|c|c|c|c|c|c|c|}
\hline No & Gender & ATP7B mutations & $\begin{array}{l}\text { Onset Age } \\
\text { (years) }\end{array}$ & $\begin{array}{l}\text { Osseomuscular } \\
\text { abnormalities (Degree }{ }^{a} \text { ) }\end{array}$ & $\begin{array}{l}\text { Neurological } \\
\text { symptoms }\end{array}$ & $\begin{array}{l}\text { Interval from } \mathrm{O} \\
\text { to } \mathrm{N} \text { (months) }\end{array}$ & $\begin{array}{l}\text { Orthopedic } \\
\text { Surgery }\end{array}$ & $\begin{array}{l}\text { Interval from S } \\
\text { to } \mathrm{N} \text { (months) }\end{array}$ \\
\hline 1 & $\mathrm{~F}$ & p.A874V + p.P992L & 10 & Genu valgum (3) & $\begin{array}{l}\text { Dysarthria, difficult } \\
\text { with writing, musk face }\end{array}$ & 8 & Yes & 2 \\
\hline 2 & M & $\begin{array}{l}\text { p.M769Hfs*26+ } \\
\text { p.R919G }\end{array}$ & 17 & Arthralgia in knee joints (2) & Dysarthria, tremor & 60 & No & - \\
\hline 3 & M & p.R778Q + p.1930del & 12 & Arthralgia in knee joints (2) & Normal & - & No & - \\
\hline 4 & $\mathrm{~F}$ & p.E332* + p.R778L & 10 & Genu varum (3) & Dysarthria, bradykinesia & 18 & Yes & 15 \\
\hline 5 & $\mathrm{~F}$ & p.R778L + p.l1148T & 13 & $\begin{array}{l}\text { Genu varum, femoral head } \\
\text { necrosis, dislocation of the } \\
\text { left shoulder (3) }\end{array}$ & Tremor & 36 & Yes & 36 \\
\hline 6 & $\mathrm{~F}$ & p.R778L + p.R778L & 15 & Talipes equinovarus (3) & Tremor writer's cramp & $\mathrm{N} / \mathrm{A}$ & Yes & $<2$ \\
\hline 7 & M & p.R778L + p.G943D & 12 & Arthralgia in knee joints (4) & Tremor, dysarthria & 84 & No & - \\
\hline 8 & M & p.R778L + p.V1106l & 3 & $\begin{array}{l}\text { Arthralgia in hip and knee } \\
\text { joints, dysplasia of thoracic } \\
\text { vertebrae (4) }\end{array}$ & Normal & $\mathrm{N} / \mathrm{A}$ & No & - \\
\hline
\end{tabular}

*Translation termination codon, $O$ osseomuscular symptoms, $N$ neurological symptom, $S$ surgery, $N / A$ not available

a Based on the published assessment scale for osseomuscular symptoms [7] 
tremor, dysarthria, writing difficulty and bradykinesia (Table 1). Then it is the moment when most diagnoses of WD were taken into consideration in these patients. The interval between the onset of osseomuscular symptoms and establishment of the diagnosis was at least 10 months (Patient 1 ) and could reach as long as 10 years (Patient 8). The neurological symptoms included tremor in four patients, dysarthria in four patients, writing difficulty in two patients and bradykinesia in one patient. Patient 1 also manifested psychiatric symptoms.

\section{Accessory examination}

The K-F ring, known as a specific sign in WD [1], was present in most patients (6/8) (Table 2). However, since most patients had developed the neurological symptoms when examining, the initial rate of K-F rings might be lower.

Serum ceruloplasmin concentration was less than $0.1 \mathrm{~g} / \mathrm{L}$ (reference: $0.2-0.4 \mathrm{~g} / \mathrm{L}$ ) in all patients. No significant abnormalities in liver function were observed, including aminotransferase, bilirubin and albumin parameters. However, the ultrasonography showed features of chronic hepatic diseases in most patients (6/8) (Table 2). All the patients were evaluated as Class A based on Child-Pugh score.

Among the five patients taking the brain MRI, four showed different degree of abnormal MRI signals. Abnormal T2 signals were discovered in three cases in basal ganglia, and two cases in the brain stem (Table 2).
For Patient 8, despite a decreased serum ceruloplasmin (0.05 g/L), he had no K-F rings, no abnormalities in brain MRI or hepatic ultrasonography. His X-rays films showed bilateral hip osteoarthritis (Fig. 1) and knee degenerative changes (Fig. 2). Notably, the thoracic MRI incidentally found the dysplasia of thoracic vertebrae (Fig. 3). Due to the absence of hepatic, neurologic symptoms and K-F ring, his diagnosis of WD was confirmed by genetic testing (Table 1 ).

\section{Outcome of treatment}

After the establishment of diagnosis, all patients received a copper chelator treatment with D-penicillamine, dimercaptosuccinic acid (DMSA) or dimercaptopropane sulfonate (DMPS). No serious related adverse reaction was observed in these patients. The patients responded generally well to the therapy. The arthralgia was all resolved and neurological symptoms showed different degrees of improvement (Table 2). However, the improvements in bone deformity were minimal.

The Patient 8 improved remarkably by treatment. After one course of intravenous DMPS (0.25 g q.d. for 6 days) and 3 months of oral DMSA (0.5 g b.i.d.), the patient felt less painful to move his legs and easier to stand up from a chair. The physical examination confirmed an improved movement of his hip joint. The range of motion was able to reach a degree of $35^{\circ}$, which increased by $40 \%$ compared with the condition 3 months ago. After 6 month of treatment, the range increased to a

Table 2 Clinical findings and treatment outcomes in eight cases of WD with osseomuscular type

\begin{tabular}{|c|c|c|c|c|c|c|c|c|}
\hline \multirow[t]{2}{*}{$\overline{\mathrm{No}}$} & \multirow{2}{*}{$\begin{array}{l}\mathrm{K}-\mathrm{F} \\
\text { ring }\end{array}$} & \multicolumn{3}{|c|}{ Neurologic Examination } & \multirow{2}{*}{$\begin{array}{l}\mathrm{CP} \\
(\mathrm{g} / \mathrm{L})\end{array}$} & \multirow{2}{*}{$\begin{array}{l}\text { Involvement on } \\
\text { brain MRI }\end{array}$} & \multirow{2}{*}{$\begin{array}{l}\text { Abdominal } \\
\text { ultrasonography }\end{array}$} & \multirow{2}{*}{$\begin{array}{l}\text { Outcomes of Chelation } \\
\text { Therapy (Degree }{ }^{a} \text { ) }\end{array}$} \\
\hline & & Strength & Tone & Reflex & & & & \\
\hline$\overline{1}$ & + & UE \& LE 5 & $\mathrm{UE} \uparrow$ & $(++)$ & $<0.02$ & Basal ganglia & Hepatic diffuse disease & $\begin{array}{l}\text { (9 months after treatment) } \\
\text { Dystonia in the right hand } \\
\text { partially relieved; blurred } \\
\text { speech persist; walking } \\
\text { better (2) }\end{array}$ \\
\hline 2 & + & UE \& LE 5 & Normal & $(++)$ & 0.02 & $\begin{array}{l}\text { Basal ganglia and } \\
\text { brain stem }\end{array}$ & $\begin{array}{l}\text { Hepatic diffuse disease, } \\
\text { splenomegaly }\end{array}$ & $\begin{array}{l}\text { ( } 3 \text { months after the treatment) } \\
\text { Pain relieved with improved } \\
\text { speech (0) }\end{array}$ \\
\hline 3 & + & UE \& LE 5 & Normal & $(++)$ & $<0.02$ & Normal & $\begin{array}{l}\text { Hepatic diffuse disease, } \\
\text { splenomegaly }\end{array}$ & $\begin{array}{l}\text { (14 months after treatment) } \\
\text { Pain relieved (0) }\end{array}$ \\
\hline 4 & + & UE \& LE 5 & UE \& LE $\uparrow$ & $(++)$ & 0.07 & N/A & Hepatic diffuse disease & $\begin{array}{l}\text { (after } 23 \text { months of inconsecutive } \\
\text { treatment) No obvious } \\
\text { improvement (3) }\end{array}$ \\
\hline 5 & N/A & UE \& LE 5 & $U E \uparrow$ & UE \& LE (+++) & 0.03 & $\begin{array}{l}\text { Basal ganglia and } \\
\text { brain stem }\end{array}$ & $\begin{array}{l}\text { Hepatic diffuse disease, } \\
\text { splenomegaly }\end{array}$ & N/A \\
\hline 6 & + & UE \& LE 5 & UE \& LE $\downarrow$ & $(++)$ & 0.03 & N/A & Normal & N/A \\
\hline 7 & + & UE 5; pLE 4; dLE 4- & UE \& LE $\downarrow$ & Knee $(+++)$ & 0.02 & N/A & $\begin{array}{l}\text { Hepatic diffuse disease, } \\
\text { splenomegaly }\end{array}$ & N/A \\
\hline 8 & - & UE 4; LE 4- & $\mathrm{LE} \uparrow$ & Knee $(+++)$ & 0.05 & Normal & Increased echogenicity & $\begin{array}{l}\text { ( } 6 \text { months after treatment) Pain } \\
\text { relieved with improved joint } \\
\text { motion (2) }\end{array}$ \\
\hline
\end{tabular}




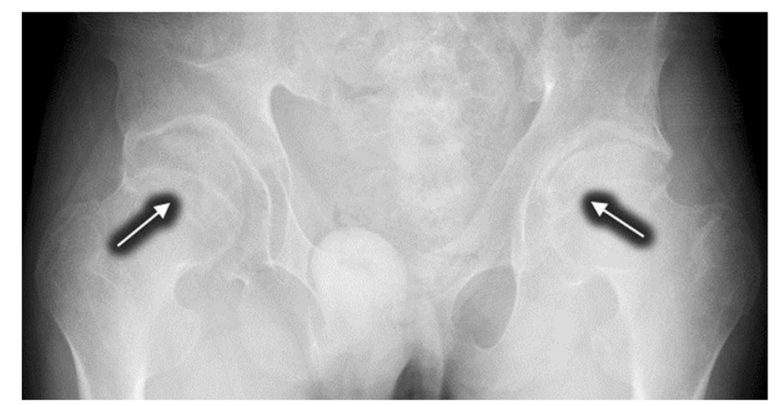

Fig. 1 The plain film showed hip osteoarthritis with narrowing joint space, incomplete articular surface and swelling joint capsule (Arrows)

degree of $80^{\circ}$ and the patient can stand and walk without the assistance of his hand.

\section{Discussion}

WD is one of the limited genetic diseases that can be clinically cured by timely treatment. The osseomuscular type of WD begins without typical hepatic and neurological symptoms, which makes the diagnosis challenging. Most patients are never considered WD until the neurological symptoms emerged. However, some typical signs were present in our patients, such as K-F rings or abnormal liver ultrasonography. Moreover, serum ceruloplasmin is a sensitive test in WD patients even without any hepatic and neurological signs. WD should be highly suspected when ceruloplasmin is below $0.1 \mathrm{~g} / \mathrm{L}$, but lower levels can also occur with aceruloplasminemia, renal or enteric protein loss, liver disease and heterozygotes for WD [10]. Therefore, if the patient has a low serum ceruloplasmin without K-F rings, the diagnosis should be based on combination of other tests. Genetic

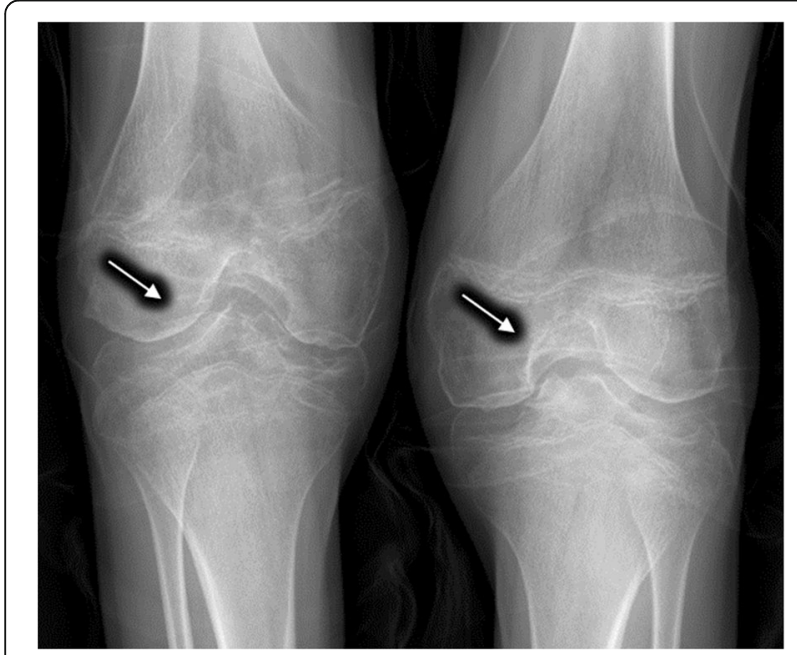

Fig. 2 The knee plain film of knee joints showed degenerative changes with articular surface hyperosteogeny and swelling joint capsule (Arrows)

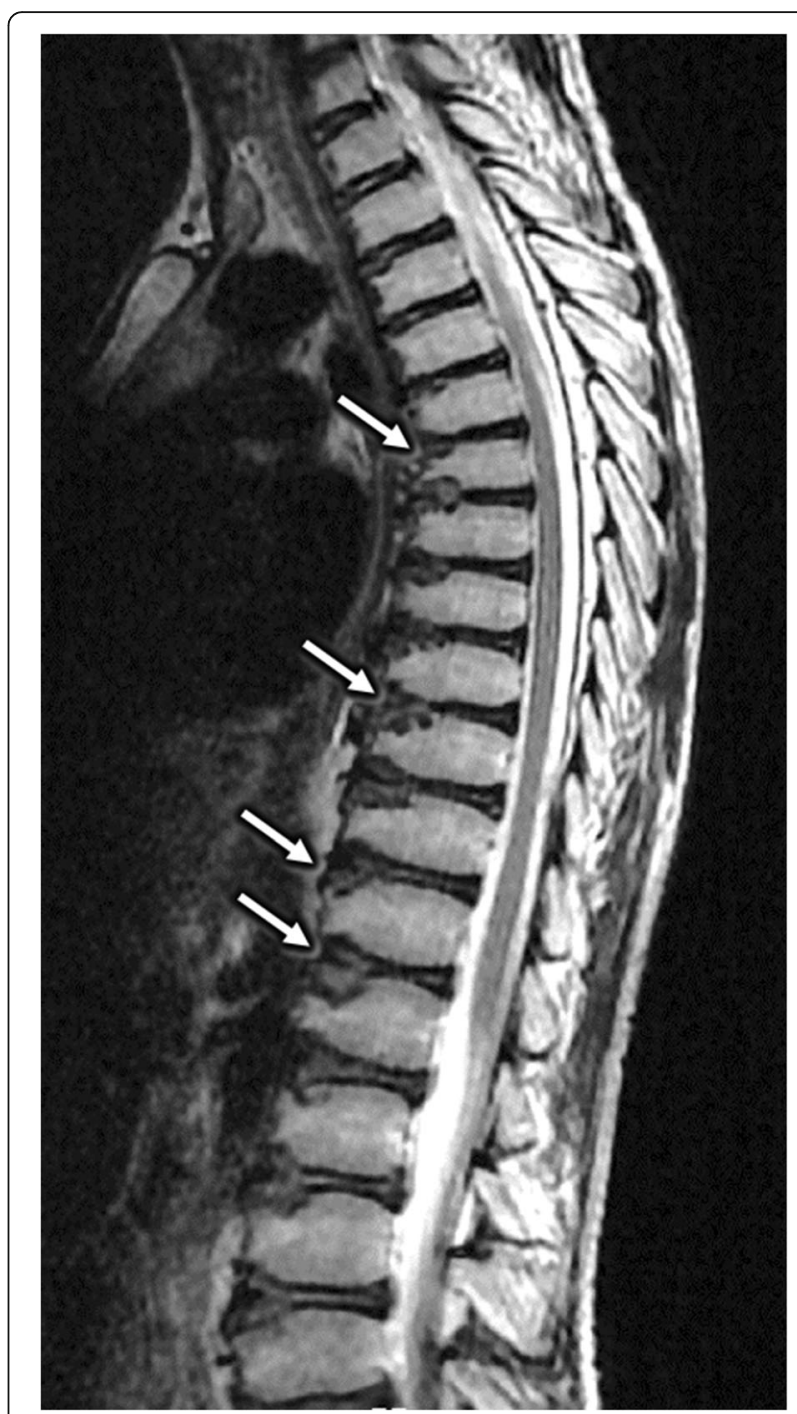

Fig. 3 The thoracic MRI showed the dysplasia of thoracic vertebrae, which had bullet-like shapes with focal cartilage defects at the front edge (Arrows)

testing is confirmatory and non-invasive, and also convenient for screening family members.

The pathogenic mechanisms underlying the musculoskeletal damage are not clear. However, it may be a result of abnormal bone metabolism. Abnormal copper deposit are found in multiple organs and structures of WD patients, including the bone, in which the copper concentration increases about four times [11]. The radiological changes of arthropathy have been frequently encountered among WD patients [11-13]. Moreover, the pathological findings suggested a chronic inflammatory process or degradation of collagen and protein secondary to a deposition of copper [14]. Besides, the calcium regulation disorder also makes the bone more vulnerable to other stimuli, which can result from vitamin D insufficiency. The hepatic damage in WD can 
impede the conversion of vitamin D to its active form, thus impaired absorption of calcium and led to osteoporosis and bone deformity [15]. The similar effects caused by the damage of kidney and parathyroid gland in WD patients are also reported [16, 17]. These pathological conditions may be corrected by timely chelation therapy and hormone supplement.

Dystonia, which is characterized by "sustained or intermittent muscle contractions causing abnormal, often repetitive, movements, postures or both", can develop into contracture and joint deformity in severe cases [18]. These conditions usually demonstrate spasticity with markedly increased muscle tone. In our patients, half of them (Patient 1, 4, 5, 8) had focal or general increase tones. However, they took 8-36 months to develop the other neurological symptoms, such as dysarthria, which usually arose with dystonia in other WD patients. In addition, Patient 8 never developed any other neurological signs in his 10-year course, which made it. Therefore, it remains obscure whether the osseomuscular type of WD is a result of long-term dystonia or a natural course of osteopathy.

\section{Conclusions}

Although most WD patients with osseomuscular type will develop neurological symptoms, it is easily misdiagnosed when it only manifests as joint pain or bone deformity. A long-term misdiagnosis may lead to irreversible damage to the musculoskeletal system, such as a permanent deformity, which often requires surgical intervention and has a poor response to the drug. Therefore, if a child or adolescent presents with unexplained musculoskeletal problems, the possibility of WD should be considered. Serum ceruloplasmin, abdominal ultrasonography, ophthalmic examinations and genetic testing will help to establish the diagnosis. Early diagnosis can initiate an effective treatment and prevent the further damage.

\section{Abbreviations \\ DMPS: Dimercaptopropane sulfonate; DMSA: Dimercaptosuccinic acid; K-F ring: Kayser-Fleischer ring; MRI: Magnetic resonance imaging; WD: Wilson's disease}

\section{Acknowledgments}

We gratefully acknowledge all participants for their help and willingness to participate this study.

\section{Funding}

This work was supported by a grant from the National Natural Science Foundation of China to Zhi-Ying Wu (81125009) and the research foundation for distinguished scholar of Zhejiang University to Zhi-Ying Wu (188020193810101/089).

\section{Availability of data and materials}

The data that support the findings of this study are available on request from the corresponding author. The data are not publicly available due to containing information that could compromise research participant privacy.

\section{Authors' contributions}

Z-YW designed the project. HY, J-J X and Q-Y D initiated the project. HY, J-J $X, Y-C$ C, Q-Y D, Y D, WN and Z-YW collected the medical information. J-JX, $Y-C C$ and $W N$ performed the sequencing and analyzed the data. HY wrote the manuscript. Z-YW commented and revised on the manuscript. Z-YW supervised all aspects of the project. All authors read and approved the final manuscript.

\section{Competing interests}

The authors declare that they have no competing interests.

\section{Consent for publication}

Consents for publication were obtained from the participants or their legal surrogates.

\section{Ethics approval and consent to participate}

The study was approved by the Ethics Committee for Human Research in Second Affiliated Hospital of Zhejiang University School of Medicine (Reference Number: 045). Informed consents were obtained from the participants or their legal surrogates prior to enrollment in the study.

\section{Author details}

'Department of Neurology and Research Center of Neurology in Second Affiliated Hospital, and the Collaborative Innovation Center for Brain Science, Zhejiang University School of Medicine, 88 Jiefang Rd, Hangzhou 310009, China. ${ }^{2}$ Department of Neurology and Institute of Neurology, First Affiliated Hospital, Fujian Medical University, Fuzhou, China. ${ }^{3}$ Department of Neurology and Institute of Neurology, Huashan Hospital, Shanghai Medical College, Fudan University, Shanghai, China. ${ }^{4}$ Joint Institute for Genetics and Genome Medicine between Zhejiang University and University of Toronto, Zhejiang University, Hangzhou, China.

Received: 6 September 2016 Accepted: 10 February 2017

Published online: 17 February 2017

\section{References}

1. Huster D. Wilson disease. Best Pract Res Clin Gastroenterol. 2010;24(5):531-9.

2. Balint G, Szebenyi B. Hereditary disorders mimicking and/or causing premature osteoarthritis. Baillieres Best Pract Res Clin Rheumatol. 2000;14(2):219-50.

3. Quemeneur AS, Trocello JM, Ea HK, Woimant F, Liote F. Miscellaneous noninflammatory musculoskeletal conditions. Musculoskeletal conditions associated with Wilson's disease. Best Pract Res Clin Rheumatol. 2011;25(5):627-36.

4. Cai YZ, Jiang TZ, Yang RM. Osseomuscular type of hepatolenticular degeneration: Report of 11 cases. Lin Chuang Shen Jing Bing Xue Za Zhi. 1994;7(3):142-4.

5. Dastur DK, Manghani DK, Wadia NH. Wilson's disease in India. I. Geographic, genetic, and clinical aspects in 16 families. Neurology. 1968;18(1 Pt 1):21-31.

6. Wu ZY, Wang N, Murong SX. Analysis of misdiagnosis of 5 cases of osseomuscular type of hepatolenticular degeneration. Chin J Pract Intern Med. 1995:15(11):669.

7. Aggarwal A, Aggarwal N, Nagral A, Jankharia G, Bhatt M. A novel Global Assessment Scale for Wilson's Disease (GAS for WD). Mov Disord. 2009;24(4): 509-18.

8. Wu ZY, Zhao GX, Chen WJ, Wang N, Wan B, Lin MT, Murong SX, Yu L. Mutation analysis of 218 Chinese patients with Wilson disease revealed no correlation between the canine copper toxicosis gene MURR1 and Wilson disease. J Mol Med (Berl). 2006;84(5):438-42.

9. Wu ZY, Wang N, Lin MT, Fang L, Murong SX, Yu L. Mutation analysis and the correlation between genotype and phenotype of Arg778Leu mutation in chinese patients with Wilson disease. Arch Neurol. 2001;58(6):971-6.

10. European Association for Study of L. EASL clinical practice guidelines: Wilson's disease. J Hepatol. 2012;56(3):671-85.

11. Xie $Y Z$, Zhang XZ, Xu XH, Zhang ZX, Feng YK. Radiologic study of 42 cases of Wilson disease. Skeletal Radiol. 1985;13(2):114-9.

12. Golding DN, Walshe JM. Arthropathy of Wilson's disease. Study of clinical and radiological features in 32 patients. Ann Rheum Dis. 1977;36(2):99-111.

13. Taly AB, Meenakshi-Sundaram S, Sinha S, Swamy HS, Arunodaya GR. Wilson disease: description of 282 patients evaluated over 3 decades. Medicine (Baltimore). 2007;86(2):112-21.

14. Kaklamanis P, Spengos M. Osteoarticular changes and synovial biopsy findings in Wilson's disease. Ann Rheum Dis. 1973;32(5):422-7. 
15. Cavallino R, Grossman H. Wilson's disease presenting with rickets. Radiology. 1968;90(3):493-4.

16. Carpenter TO, Carnes Jr DL, Anast CS. Hypoparathyroidism in Wilson's disease. N Engl J Med. 1983;309(15):873-7.

17. Monro P. Effect of treatment on renal function in severe osteomalacia due to Wilson's disease. J Clin Pathol. 1970;23(6):487-91.

18. Chin TY, Duncan JA, Johnstone BR, Graham HK. Management of the upper limb in cerebral palsy. J Pediatr Orthop B. 2005;14(6):389-404.

Submit your next manuscript to BioMed Central and we will help you at every step:

- We accept pre-submission inquiries

- Our selector tool helps you to find the most relevant journal

- We provide round the clock customer support

- Convenient online submission

- Thorough peer review

- Inclusion in PubMed and all major indexing services

- Maximum visibility for your research

Submit your manuscript at www.biomedcentral.com/submit 